\title{
Predictability of western North Pacific typhoon activity and its factors using DEMETER coupled models
}

\author{
SUN JianQi ${ }^{1 *} \&$ CHEN HuoPo ${ }^{1,2}$ \\ ${ }^{1}$ Nansen-Zhu International Research Centre (NZC), Institute of Atmospheric Physics, Chinese Academy of Sciences, Beijing 100029, China; \\ ${ }^{2}$ Graduate University of Chinese Academy of Sciences, Beijing 100049, China
}

Received March 16, 2011; accepted June 16, 2011; published online August 30, 2011

\begin{abstract}
Climate prediction using a coupled model with a one-tier scheme is an important research direction. In this study, based on 19742001 hindcasts obtained from the "Development of a European Multimodel Ensemble system for seasonal to inTERannual prediction" (DEMETER) project, the capability of coupled general circulation models (CGCMs) to predict six climatic factors that have a close relationship with the western North Pacific typhoon activity is investigated over summer (June-October). Results indicate that all six DEMETER CGCMs well predict the six factors. Using the statistical relationship between these six factors and the typhoon frequency, the ability of the CGCMs to predict typhoon frequency is further explored. It is found that the six CGCMs also well predict the variability in typhoon frequency. Comparison analysis shows that the prediction skill of the statistical downscaling method is much better than that of the raw CGCMs. In addition, the six-model ensemble has the best prediction performance. This study suggests that combining a multi-model ensemble and statistical downscaling greatly improves the CGCM prediction skill, and will be an important research direction for typhoon prediction.
\end{abstract}

typhoon prediction, coupled general circulation model, statistical downscaling, multi-model ensemble prediction, DEMETER

Citation: $\quad$ Sun J Q, Chen H P. Predictability of western North Pacific typhoon activity and its factors using DEMETER coupled models. Chinese Sci Bull, 2011, 56: 3474-3479, doi: 10.1007/s11434-011-4640-7

A typhoon is one of the most important high-impact extreme weather events in the western North Pacific (WNP). Its occurrence is accompanied by strong wind and heavy precipitation, which greatly affect navigation and people's lives in eastern Asia. Typhoons have long been a hot topic in meteorological research. Over the past several decades, a number of studies have investigated typhoon variability and its causes. It has been found that typhoon activity is complex because of there being many climatic factors. Over the WNP, factors such as the local sea surface temperature (SST), convection condition, zonal wind shear magnitude, and position and intensity of the intertropical convergence zone directly affect typhoon activity [1-8]. On a larger spatial scale, climate systems, such as El Niño/La Niña-Southern Oscillation [9-14], quasi-biannual oscillation [15,16], atmospheric intraseasonal oscillation [17,18], Antarctic

*Corresponding author (email: sunjq@mail.iap.ac.cn)
Oscillation [19,20], North Pacific Oscillation [21], North Pacific sea ice [22], spring Hadley circulation [23], and Asian-Pacific Oscillation [24,25] indirectly affect typhoon activity by changing local atmospheric and oceanic conditions in the WNP. The above research on typhoons has been well reviewed by Wang et al. [26].

According to influencing factors, two prediction methods for WNP typhoon activity have been developed. One is a statistical method that uses preceding typhoon-related signals of atmospheric and oceanic systems to develop a prediction model and then make a prediction [27-30]. In recent WNP typhoon prediction, the statistical method has performed well. However, we know that the connection between two indirectly related climatic systems can change over time [31,32]. Specifically, two systems may be covariant in some periods but independent in other periods. Therefore, there is the potential problem with the purely statistical forecasting model that predictors suitable for 
some periods could be unsuitable for other periods [33]. To overcome this limitation of the purely statistical prediction, a second prediction method-dynamical prediction based on a climate model—was developed with improvements in computer technology and climate models. This method makes predictions using predictors from the climate model, which directly affect typhoon genesis. In the dynamical prediction system, therefore, the relationship between the predictor and predictand does not change over time. The dynamical method has been an important development in typhoon prediction in recent times. To date, only a few organizations have made real-time predictions of WNP typhoon activity (e.g. European Centre for Medium-Range Weather Forecasts, International Research Institute for Climate and Society, and Institute of Atmospheric Physics) [5,34]. There are two prediction schemes for the dynamical prediction method. One is a two-tier scheme and the other is a one-tier scheme. Additionally, there are two approaches for predicting typhoons. One is a direct approach in which typhoon variability is predicted by detecting typhoon-like tropical cyclones (TCs) in the dynamical prediction systems $[35,36]$, and the other is an indirect approach in which typhoon activity is predicted by investigating the variability of large-scale climate factors that are directly associated with typhoon genesis. Since the former approach detects the typhoon in the climate models directly, the models need to be of high resolution. However, most current coupled general circulation models (CGCMs) have insufficient resolution to reasonably resolve the exact features of TCs, which largely limits these models' ability to detect typhoons and further predict typhoon variability. The latter approach is more applicable, since all climate models with different resolution have some ability to predict large-scale circulation variability over the WNP, and consequently, they can be used to predict typhoon activity over the region. However, the predictive skill of the indirect approach is mainly dependent on the climate model's ability to simulate typhoon-related climatic factors over the WNP. Previous studies have shown that the two-tier dynamical system has some capability of simulating and predicting WNP typhoon activity and its related large-scale circulations [7]. Therefore, it is natural to ask how a one-tier model system performs in predicting WNP typhoon-related climatic factors and typhoon variability. This question remains open. This study first investigates the capability of six coupled models to predict typhoonrelated large-scale factors over the WNP, then further explores the capability of these coupled models to predict the WNP typhoon frequency, and finally discusses the advantage of the multi-model ensemble in the prediction of typhoon activity.

\section{Model and data}

Hindcasts of CGCMs are archived by the "Development of a European Multimodel Ensemble system for seasonal to inTERannual prediction" (DEMETER) project [37]. The DEMETER project takes seven CGCMs from CERFACS (European Centre for Research and Advanced Training in Scientific Computation, France), ECMWF (European Centre for Medium-range Weather Forecasts), INGV (Istituto Nazionale de Geofisica e Vulcanologia, Italy), LODYC (Laboratoire d'Océanographie Dynamique et de Climatologie, France), CNRM (Centre National de Recherches Météorologiques, Météo-France, France), UKMO (Met Office, UK), and MPI (Max-Planck Institut für Meteorologie, Germany). These CGCMs were installed on a single supercomputer and a series of hindcasts were produced with common archiving and diagnostic software. By systematically analyzing the hindcasts of these seven CGCMs, DEMETER attempts to advance our understanding of multimodel ensemble prediction. The DEMETER hindcasts are started four times per year at 0000 GMT on February 1, May 1, August 1, and November 1. Each hindcast is integrated for six months and has nine members. Among the seven models, six have a common hindcast period of 1974-2001. Synthetically considering the ensemble analysis number and the quality of the typhoon data before the mid-1970s [38,39], the study period in this paper is confined to 1974-2001. Since the major typhoon season is June-October, the hindcasts from 0000 GMT on May 1 are analyzed in this study. In this manner, we investigate the ability of the CGCMs to forecast summer typhoon activity (June-October) in terms of 1-month lead predictions, which has the potential to advance current operational forecasting of WNP typhoon activity.

Monthly ECMWF reanalysis data (ERA-40) [40] are used to investigate the simulation of typhoon-related circulations with coupled models. The analysis variables include wind variables, sea-level pressure (SLP), specific humidity, divergence, vorticity, and surface air temperature. The typhoon frequency is derived from the Joint Typhoon Warning Center TC dataset over the WNP $\left(100^{\circ} \mathrm{E}-170^{\circ} \mathrm{W}, 0^{\circ}-\right.$ $55^{\circ} \mathrm{N}$ ). Depending on the maximum sustained wind speed, the TCs are generally divided into three classes: tropical depressions, tropical storms, and typhoons. In this study, the term typhoon refers to either a tropical storm or a typhoon with maximum wind speed exceeding $17.2 \mathrm{~m} / \mathrm{s}$, which differs from the traditional definition of a typhoon.

\section{Climatic factors of WNP typhoon activity}

It is well known that there are many climatic factors of typhoon activity. Factors having direct influence on typhoon activity are mainly local to the WNP. Figure 1 shows that when there is greater typhoon frequency, over the lower latitudes of the North Pacific, an anomalous depression accompanies positive vorticity anomalies and there is more moisture at a lower level, there are divergent anomalies at 

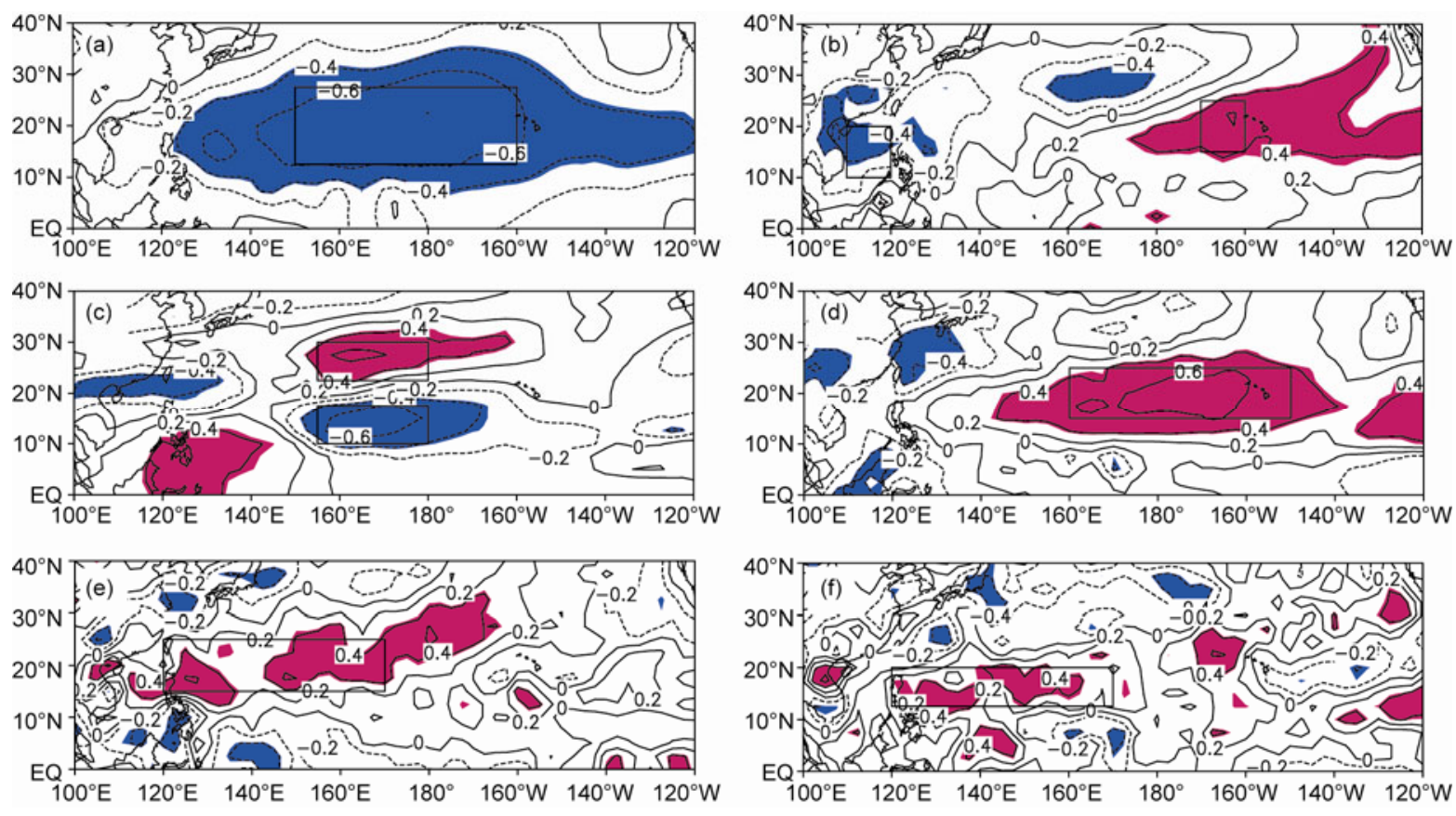

Figure 1 Distributions of the coefficients of correlation of observed typhoon frequency with observed (a) SLP, (b) SST, (c) magnitude of zonal wind shear between 200 and $850 \mathrm{hPa}$, (d) specific humidity at $850 \mathrm{hPa}$, (e) vorticity at $850 \mathrm{hPa}$, and (f) divergence at $200 \mathrm{hPa}$. The red (blue) shading indicates the areas where the correlations are significant at the $95 \%$ confidence level. The rectangles indicate the key regions for each variable where the correlations are strongest.

the upper level, the zonal wind shear between 200 and 850 $\mathrm{hPa}$ is weaker, and the SST has an "east warm-west cold" dipole pattern (Here the surface air temperature is used to represent the SST, since DEMETER did not provide SST data). The combined effect of these climatic factors provides favorable dynamical, thermal, and humid conditions for typhoon genesis. Since the influence of all these six climatic factors on typhoon activity has been revealed in previous studies as reviewed in the introduction, we do not investigate them individually here.

This study investigates the quantitative contribution of the six climatic factors to variability in the typhoon frequency, with the aim of establishing a basis to evaluate the prediction capability of the coupled model. Therefore, the averages of these six variables over key regions (rectangles in Figure 1) are calculated as indices to diagnose the quantitative relationship between the six factors and typhoon frequency. For the variables whose correlations with typhoon frequency have positive and negative key regions (rectangles in Figure 1), indices are defined as the difference between the mean values of the negative and positive key regions. The key regions for each variable are $12.5^{\circ}-27.5^{\circ} \mathrm{N}, 150^{\circ} \mathrm{E}-160^{\circ} \mathrm{W}$ for the SLP index, $10^{\circ}-20^{\circ} \mathrm{N}$, $110^{\circ}-120^{\circ} \mathrm{E}$ and $15^{\circ}-25^{\circ} \mathrm{N}, 170^{\circ}-160^{\circ} \mathrm{W}$ for the SST index, $10^{\circ}-17.5^{\circ} \mathrm{N}, 155^{\circ} \mathrm{E}-180^{\circ}$ and $22.5^{\circ}-30^{\circ} \mathrm{N}, 155^{\circ} \mathrm{E}-180^{\circ}$ for the zonal wind shear index, $15^{\circ}-25^{\circ} \mathrm{N}, 160^{\circ} \mathrm{E}-150^{\circ} \mathrm{W}$ for specific humidity at $850 \mathrm{hPa}, 15^{\circ}-25^{\circ} \mathrm{N}, 120^{\circ}-170^{\circ} \mathrm{E}$ for the vorticity index at $850 \mathrm{hPa}$, and $12.5^{\circ}-20^{\circ} \mathrm{N}, 120^{\circ}-170^{\circ} \mathrm{E}$ for the divergence index at $200 \mathrm{hPa}$. Table 1 lists the
Table 1 Coefficients of correlation of the observed typhoon frequency with the observed six factor indices

\begin{tabular}{|c|c|c|c|c|c|c|}
\hline & $x_{1}$ & $x_{2}$ & $x_{3}$ & $x_{4}$ & $x_{5}$ & $x_{6}$ \\
\hline $\begin{array}{c}\text { Correlation } \\
\text { coefficient }\end{array}$ & $-0.76^{*}$ & $-0.68^{*}$ & $-0.72^{*}$ & $0.70^{*}$ & $0.61^{*}$ & $0.63^{*}$ \\
\hline
\end{tabular}

coefficients of correlation between the six factor indices and the typhoon frequency. It shows that all correlation coefficients are high, with a minimum value of 0.61 and maximum value of -0.76 , and all correlations are significant at the $99 \%$ confidence level. To quantitatively study the ability of the six factors to describe the typhoon frequency variability, we use the six factor indices to linearly fit the typhoon frequency through multiple linear regression:

$$
\begin{aligned}
y= & -1.45 x_{1}-1.02 x_{2}-0.90 x_{3}+0.82 x_{4}-1.59 x_{5} \\
& +1.86 x_{6}+20.07,
\end{aligned}
$$

where $y$ is the simulated typhoon frequency, and $x_{1}$ to $x_{6}$ are the normalized indices of SLP, SST, magnitude of zonal wind shear between 200 and $850 \mathrm{hPa}$, specific humidity at $850 \mathrm{hPa}$, vorticity at $850 \mathrm{hPa}$, and divergence at $200 \mathrm{hPa}$, respectively.

Figure 2 shows the observed and simulated (using eq. (1)) typhoon frequency over the WNP. It suggests that the observed and simulated typhoon frequencies have highly consistent 


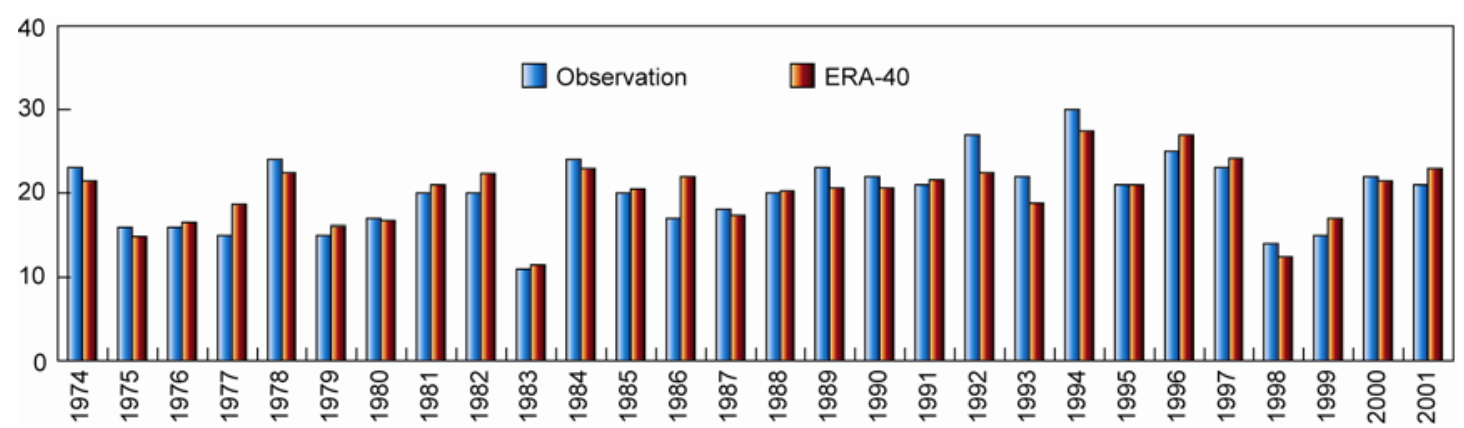

Figure 2 Observed typhoon frequency and typhoon frequency simulated using the six observed factor indices through multiple linear regression.

variability. The coefficient of correlation between these two typhoon frequencies is 0.88 , with the correlation being significant at the $99 \%$ confidence level. The root-mean-squareerror (RMSE) of the simulated frequency is 2.0 relative to the observation. This result indicates that such linear combination of the six typhoon-related factors based on multiple linear regression well describes the typhoon frequency variability, explaining more than $77 \%$ of the observed variance of typhoon frequency with low RMSE.

\section{Prediction capability of the coupled models for the typhoon-related factors in the WNP}

The result obtained in the previous section shows that using the SLP, lower-level vorticity and specific humidity, zonal wind shear, upper-level divergence and SST can well describe the typhoon frequency variability over the WNP. We now investigate the ability of the DEMETER coupled models to predict the six-factor variability, which is closely related to the ability of the coupled models to predict typhoon frequency variability over the WNP.

Table 2 gives the coefficients of correlation of the six factor indices between the ERA-40 and the coupled models. The definition of these six factors is consistent between EAR-40 and the coupled models. With developments in the past several decades, coupled models have become considerably better at simulating typhoon-related large-scale climatic factors. As shown in columns 1 to 3 of Table 2, the coupled models well predict the variability of the SLP, SST and zonal wind shear, with correlation coefficients between 0.58 and 0.85 , with all correlations being significant at the $99 \%$ confidence level. Comparatively, the simulation ability for the vorticity, divergence, and specific humidity is lower. The reason is that vorticity, divergence and specific humidity have more complex variability and a smaller spatial scale than SLP, SST, and zonal wind shear, which leads to greater difficulty in the coupled-model simulation. In general, however, the six coupled models perform well in predicting typhoon-related climatic factors over the WNP. Except in the case of the divergence index at $200 \mathrm{hPa}$ predicted by the fifth coupled model (for which the correlation is not
Table 2 Coefficients of correlation between the predicted typhoon-related factors by the six models and their ensemble and observed typhoon-related factors ${ }^{\text {a) }}$

\begin{tabular}{lcccccc}
\hline & $x_{1}$ & $x_{2}$ & $x_{3}$ & $x_{4}$ & $x_{5}$ & $x_{6}$ \\
\hline Model 1(ECMWF) & $0.58^{* * * *}$ & $0.80^{* * *}$ & $0.61^{* * *}$ & $0.42^{* *}$ & $0.53^{* * * *}$ & $0.45^{* *}$ \\
Model 2 (INGV) & $0.68^{* * *}$ & $0.66^{* * *}$ & $0.63^{* * *}$ & $0.37^{* *}$ & $0.54^{* * *}$ & $0.38^{* *}$ \\
Model 3 (LODYC) & $0.60^{* * * *}$ & $0.83^{* * *}$ & $0.60^{* * *}$ & $0.45^{* *}$ & $0.50^{* * * *}$ & $0.58^{* * *}$ \\
Model 4 (CNRM) & $0.73^{* * *}$ & $0.85^{* * *}$ & $0.65^{* * *}$ & $0.51^{* * *}$ & $0.73^{* * *}$ & $0.38^{* * *}$ \\
Model 5 (MPI) & $0.64^{* * *}$ & $0.65^{* * *}$ & $0.62^{* * *}$ & $0.54^{* * *}$ & $0.33^{* *}$ & 0.28 \\
Model 6 (UKMO) & $0.72^{* * * *}$ & $0.74^{* * *}$ & $0.78^{* * *}$ & $0.60^{* * *}$ & $0.60^{* * *}$ & $0.51^{* * *}$ \\
Ensemble & $0.74^{* * * *}$ & $0.84^{* * *}$ & $0.76^{* * *}$ & $0.59^{* * *}$ & $0.69^{* * * *}$ & $0.69^{* * *}$ \\
\hline
\end{tabular}

a) $x_{1}$ to $x_{6}$ are the normalized indices of SLP, SST, magnitude of zonal wind shear between 200 and $850 \mathrm{hPa}$, specific humidity at $850 \mathrm{hPa}$, vorticity at $850 \mathrm{hPa}$, and divergence at $200 \mathrm{hPa}$. $* * * * * * * *$ indicate correlation significant at the $99 \% / 95 \% / 90 \%$ confidence levels.

significant at the $90 \%$ confidence level), the predicted indices significantly correlate with the observations.

In model simulations, the multi-model and multi-member ensemble is widely applied as one effort to reduce uncertainty resulting from internal variability and differences among models. The above result for each model is a ninemember ensemble result. Here the six-model ensemble is further studied. In the present analysis, we only take a simple six-model mean (i.e. the model weight is not considered here). As shown in Table 2, the ensemble generally has higher prediction ability. The six correlation coefficients have a minimum of 0.59 and maximum of 0.84 , and thus, there is less uncertainty arising from poor model performance in predicting some variables.

\section{Capability of the coupled models to predict typhoon frequency in the WNP}

The previous section revealed that the DEMETER coupled models have good prediction capacity for the six typhoonrelated climatic factors. In this section, we investigate whether the coupled models can predict the observed relationship between these six factors and the typhoon frequency. Therefore, we substitute the six factor indices predicted by the six coupled models for the observed indices in eq. (1) but do not 
change the coefficients in eq. (1), checking the ability of these six CGCMs to predict the WNP typhoon frequency using the six well-predicted typhoon-related climatic factors. Since the coefficients in eq. (1) are derived from observation and the same for the six coupled models, the typhoon frequency predicted using eq. (1) is an independent sample test for each model, and the prediction results obtained with the different models can be objectively compared.

Table 3 shows that different models have different skill in predicting the typhoon frequency variability. The coefficients of correlation between the observed and predicted typhoon frequencies are between 0.54 and 0.64 , with the correlation being significant at the $99 \%$ confidence level. The RMSEs of the six coupled models are between 3.3 and 4.0. Figure 3 shows the observed and predicted year-to-year typhoon frequencies. It suggests that the predicted and observed frequencies have highly consistent variability. The years 1983, 1998 and 1999 with much less typhoon frequency are well predicted by the six coupled models. The multi-model ensemble has the best prediction skill; as shown in Table 3 and Figure 3, the variability of the observed typhoon frequency and the variability of the typhoon frequency predicted with the multi-model ensemble are more consistent than is the case for individual models. The coefficient of correlation between the observed and multi-model ensemble-predicted typhoon frequencies is 0.68 and the RMSE is 3.1, which is the best result achieved.

The above analysis indicates that the six DEMETER coupled models have good prediction capability for typhoon frequency, while the multi-model ensemble has the best performance.

\section{Conclusions}

Using hindcasts of six DEMETER coupled models over the period of 1974-2001, the prediction capability of the coupled models for six typhoon-related climatic factors is investigated. The results indicate that these six coupled models are well able to predict the variability of the six factors, especially the variability of large-scale circulations and SST. Moreover, the prediction ability of the coupled models for the typhoon frequency is further explored. It is found that the coupled models also well predict the typhoon frequency variability over the WNP after employing statistical downscaling. The six-model ensemble has the best performance. Taking an objective approach to detect typhoon-like tropical cyclones in the coupled models, Vitart [36] investigated the prediction capability of the DEMETER coupled models for typhoon frequency over the WNP. He showed that there are only three coupled models for which predicted typhoon frequencies have significant correlation with the observation. In this study, however, employing statistical dynamical forecasting, the prediction skill of the coupled models for the typhoon frequency variability is largely improved. The correlations between observed typhoon frequencies and typhoon frequencies predicted by the six coupled models are all significant at the $99 \%$ confidence level.

For objective comparison of model predictions, the definitions for all indices and the statistical downscaling formula for the typhoon frequency prediction are determined from observations and are consistent among models. However, different coupled models have different prediction features for the typhoon frequency and its related climate factors. For example, the key regions could differ among models or between a model and observations. Additionally, different models might have different prediction skill for different factors. Thus, in operational forecasting, different organizations should combine these six typhoon-related factors optimally on the basis of their model's features, which would further improve the model's prediction skill as compared to the objective definition and combination of the typhoon-related factors based on the observations in this study.

Making a prediction by selecting the best prediction

Table 3 Coefficients of correlation between the typhoon frequencies derived with the six models and their ensemble and observed typhoon frequencies over the WNP

\begin{tabular}{|c|c|c|c|c|c|c|c|}
\hline & Model 1 ECMWF & Model 2 INGV & Model 3 LODYC & Model 4 CNRM & Model 5 MPI & Model 6 UKMO & Ensemble \\
\hline Correlation coefficient & $0.54^{*}$ & $0.54^{*}$ & $0.63^{*}$ & $0.59^{*}$ & $0.64^{*}$ & $0.61^{*}$ & $0.68^{*}$ \\
\hline Root-mean-square-error & 4.0 & 3.6 & 3.5 & 3.4 & 3.3 & 3.7 & 3.1 \\
\hline
\end{tabular}

* indicates that the correlations are significant at the $99 \%$ confidence level.

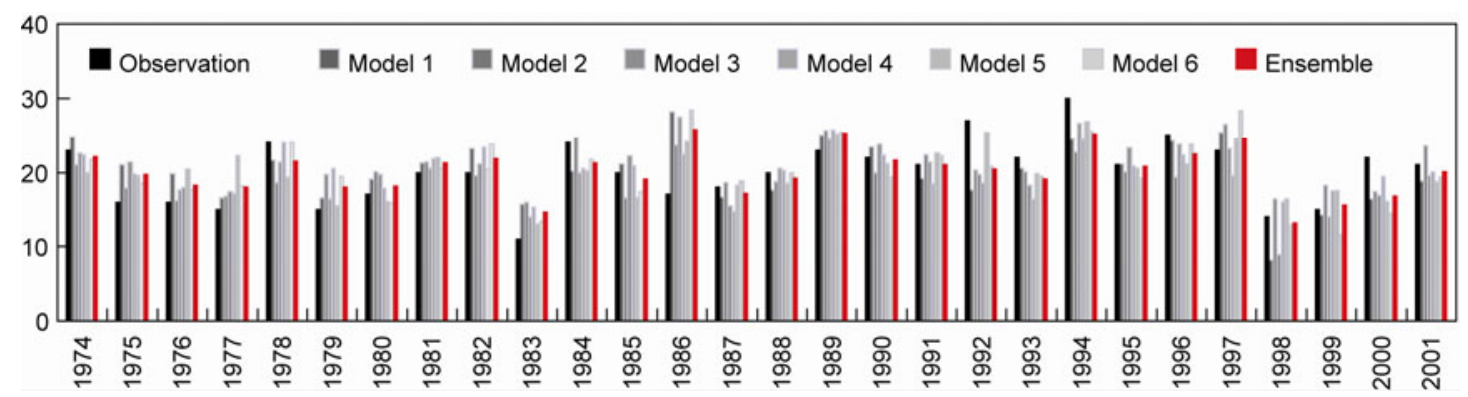

Figure 3 Predictions made with the six models and their ensemble and observed typhoon frequencies over the WNP. 
signals from the coupled model can improve a model's prediction capability [41]. This study developed a prediction method that combines statistical downscaling with coupled models as an important tool to improve the ability of a coupled model for typhoon frequency. Using this tool, many coupled climate models with high or low resolution can be used to predict typhoon activity, which consequently benefits super-ensemble prediction of typhoon activity and improves the dynamical prediction of typhoons.

The authors would like to thank two anonymous reviewers for suggestions that improved this paper. This work was supported by the Special Fund for Public Welfare Industry (meteorology) (GYHY200906018), the Key Program of the Chinese Academy of Sciences (KZCX2-YW-Q03-3), the National Basic Research Program of China (2009CB421406), and the Norwegian Research Council Project "East-Asia DecCen.”.

1 Gray W M. Global view of the origin of topical disturbance and storms. Mon Weather Rev, 1968, 96: 669-700

2 Ding Y H, Fan H J, Xue Q F, et al. Preliminary study on the multi-typhoon development in the tropical convergence zone (in Chinese). Chin J Atmos Sci, 1977, 1: 89-98

3 Chen L S, Ding Y H. Introduction to the Western Pacific Typhoons (in Chinese). Beijing: Science Press, 1979. 491

4 Ding Y H, Wright E R. The large scale circulation condition for the western Pacific typhoon genesis (in Chinese). Acta Oceanol Sin, 1983, 5: 561-574

5 Wang H J, Lang X M, Fan K, et al. Real-time climate prediction experiment for the typhoon frequency in the western North Pacific for 2006 (in Chinese). Clim Environ Res, 2006, 11: 133-137

6 Yuan J N, Wang D X, Wang Q L, et al. A 28-year climatological analysis of size parameters for northwestern Pacific tropical cyclones. Adv Atmos Sci, 2007, 24: 24-34

7 Lang X M, Wang H J. Can the climate background of western North Pacific typhoon activity be predicted by climate model? Chinese Sci Bull, 2008, 53: 2392-2399

8 Chen G H, Huang R H. Influence of monsoon over the warm pool on interannual variation on tropical cyclone activity over the western North Pacific. Adv Atmos Sci, 2008, 25: 319-328

9 Chan J C L. Tropical cyclone activity in the northwest Pacific in relation to the El Niño/ Southern Oscillation phenomenon. Mon Weather Rev, 1985, 113: 599-606

10 Li C Y. El Niño and the western Pacific typhoon activity (in Chinese). Chinese Sci Bull, 1985, 30: 1087-1089

11 Lander M A. An exploratory analysis of the relationship between tropical storm formation in the western North Pacific and ENSO. Mon Weather Rev, 1994, 122: 636-651

12 He M, Song W L, Chen X F. Typhoon activity in the northwest Pacific in relation to El Niño/La Niña events (in Chinese). J Trop Meteor, 1999, 15: 17-25

13 Wang B, Chan J C L. How does ENSO regulate tropical storm activity over the western North Pacific? J Clim, 2002, 15: 1643-1658

14 Camargo S J, Sobel A H. Western North Pacific tropical cyclone intensity and ENSO. J Clim, 2005, 18: 2996-3006

15 Gray W M. Atlantic seasonal hurricane frequency. Part I: El Niño and $30 \mathrm{hPa}$ quasi-biennial oscillation influences. Mon Weather Rev, 1984, 112: $1649-1668$

16 Chan J C L. Tropical cyclone activity in the western North Pacific in relation to the stratospheric quasi-biennial oscillation. Mon Weather Rev, 1995, 123: 2567-2571

17 Liebmann B, Hendon H H, Glick J D. The relationship between tropical cyclones of the western Pacific and Indian Oceans and the Mad-
den-Julian oscillation. J Meteorol Soc Jpn, 1994, 72: 401-411

18 Zhu C W, Nakazawa T, Li J P. Modulation of tropical depression/cyclone over the Indian-western Pacific oceans by Madden-Julian oscillation (in Chinese). Acta Meteorol Sin, 2004, 62: 42-51

19 Wang H J, Fan K. Relationship between the Antarctic oscillation and the western North Pacific typhoon frequency. Chinese Sci Bull, 2007, 52: 561-565

20 Ho C H, Kim J H, Kim H S, et al. Possible influence of the Antarctic Oscillation on tropical cyclone activity in the western North Pacific. J Geophys Res, 2005, 110: D19104, doi:10.1029/2005JD005766

21 Wang H J, Sun J Q, Fan K. Relationship between the North Pacific oscillation and the typhoon/hurricane frequencies. Sci China Ser DEarth Sci, 2007, 50: 1409-1416

22 Fan K. North Pacific sea ice cover, a predictor for the western North Pacific typhoon frequency? Sci China Ser D-Earth Sci, 2007, 50: 1251-1257

23 Zhou B T, Cui X. Hadley circulation signal in the tropical cyclone frequency over the erstern North Pacific. J Geophys Res, 2008, 113: D16107, doi:10.1029/2007JD009156

24 Zhou B T, Cui X, Zhao P. Relationship between the Asian-Pacific oscillation and the tropical cyclone frequency in the western North Pacific. Sci China Ser D-Earth Sci, 2008, 51: 380-385

25 Zou Y, Zhao P. Relation of summer Asian-Pacific oscillation to tropical cyclone activities over the coastal waters of China. Acta Meteorol Sin, 67: 708-715

26 Wang H J, Fan K, Sun J Q, et al. Some advances in the researches of the western North Pacific typhoon climate variability and prediction (in Chinese). Chin J Atmos Sci, 2007, 31: 1076-1081

27 Chan J C L, Shi J E, Lam C M. Seasonal forecasting of t ropical cyclone activity over western North Pacific and the South China Sea. Wea ther Forecast, 1998, 13: 997-1003

28 Chan J C L, Shi J E, Liu K S. Improvements in the seasonal forecasting of tropical cyclone activity over the western North Pacific. Weather Forecast, 2001, 16: 491-498

29 Fan K. New predictors and a new prediction model for the typhoon frequency over western North Pacific. Sci China Ser D-Earth Sci, 2007, 50: 1417-1423

30 Fan K, Wang H J. A new approach to forecasting typhoon frequency over the western North Pacific. Weather Forecast, 2009, 24: 974-986

31 Wang H J. The instability of the East Asian summer monsoon ENSO relations. Adv Atmos Sci, 2002, 19: 1-11

32 Sun J Q, Wang H J, Yuan W. Decadal variations of the relationship between the summer North Atlantic Oscillation and middle East Asian air temperature. J Geophys Res, 2008, 113: D15107, doi: 10.1029/2007JD009626

33 Sun J Q, Ahn B J. A GCM-Based Forecasting Model for the Landfall of Tropical Cyclones in China. Adv Atmos Sci, 2011, doi: 10. 1007/ s00376-011-0122-8

34 Camargo S J, Barnston1 A G, Klotzbach P J, et al. Seasonal tropical cyclone forecasts. WMO Bull, 2007, 56: 297-309

35 Camargo S J, Zebiak S E. Improving the detection and tracking of tropical cyclones in atmospheric general circulation models. Weather Forecast, 2002, 17: 1152-1162

36 Vitart F. Seasonal forecasting of tropical storm frequency using a multi-model ensemble. Quart J Royal Meteorol Soc, 2006, 132: 647-666

37 Palmer T N, Alessandri A, Andersen U, et al. Development of a European multimodel ensemble system for seasonal-to-interannual prediction (DEMETER). Bull Am Meteorol Soc, 2004, 85: 853-872

38 Zou Y, Zhao P, Qiao L. A method of estimating typhoon central wind based on sea level pressure of the Typhoon Yearbook of China. J Trop Meteorol, 2009, 16: 20-26

39 Zou Y, Zhao P. Comparison of some tropical cyclone datasets and correction of yearbook data. J Trop Meteorol, 2010, 16: 109-114

40 Uppala S M, Kallberg P W, Simmons A J, et al. The ERA-40 Reanalysis. Quart J Royal Meteorol Soc, 2005, 131: 2961-3012

41 Wang H J, Fan K. A new scheme for improving the seasonal prediction of summer precipitation anomalies. Weather Forecast, 2009, 24: 548-554

Open Access This article is distributed under the terms of the Creative Commons Attribution License which permits any use, distribution, and reproduction in any medium, provided the original author(s) and source are credited. 